\title{
THE PSYCHIATRIC PREDICTION OF DANGEROUSNESS
}

\author{
Bernard L. Diamond $\dagger$
}

Recently there have been several horrendous cases of multiple murders committed in California by persons who had either been "cleared" by psychiatrists or who had been discharged from mental institutions as "no longer dangerous." Such cases invariably result in strong demands on the part of law enforcement officials and from the public for psychiatrists to "do something" to protect against such irrational killings.

In 1964, Edmund E. Kemper III, a fifteen-year-old boy, shot and killed his grandmother and grandfather. He was committed to Atascadero State Hospital, ${ }^{2}$ where he was confined and treated for five years. He was returned to the jurisdiction of the California Youth Authority and in 1970, being twenty-one, was released. In September 1972, he applied to the court to have his records sealed. ${ }^{3}$ Feeling some uncertainty about Kemper's mental condition, the court appointed two psychiatrists to examine him. Both psychiatrists reported that he was not dangerous or otherwise a threat to society. However, it later was revealed that he had murdered and dismembered six young girls, his mother, and one of his mother's friends during the course of a year. One of the murders had been accomplished four days before the psychiatric examinations which declared him harmless. ${ }^{4}$

Such cases, understandably, greatly alarm the public and hardly inspire confidence in the ability of psychiatrists to predict

$\dagger$ Professor of Law and Criminology, University of California, Berkeley; Clinical Professor of Psychiatry, University of California, San Francisco. A.B. 1935, University of California, Berkeley; M.D. 1939, University of California, San Francisco.

'See, e.g., NewSWEEK, June 4, 1973, at 69.

${ }^{2}$ Atascadero is a California institution for the criminally insane and mentally disordered sex offenders.

${ }^{3}$ Cal. Penal Code $\S 1203.45$ (West Supp. 1974) provides for the sealing of records of persons who were under the age of 18 at the time of the arrest. "Thereafter such conviction, arrest, or other proceeding shall be deemed not to have occurred, and the petitioner may answer accordingly any question relating to their occurrence." Id. \& 1203.45(a). This section was not intended to apply to minors convicted of felonies, but Kemper had not been so convicted because of his mental condition.

i See note 1 supra. 
dangerousness. Nevertheless, the courts rely heavily upon such psychiatric predictions both in criminal cases and in civil commitments for involuntary hospitalization. Particularly in recent years, with the growing emphasis on civil rights of the mentally ill, the state of being dangerous to self or others may be the only ground for involuntary hospitalization under progressive statutes. ${ }^{5}$ Rubin estimates that "[a]pproximately 50,000 mentally ill persons per year are predicted to be dangerous and preventatively detained for society's and their protection as well as treatment."6

Can psychiatrists predict danger with reasonable accuracy? Are there well established clinical symptoms which, if present, can be relied upon to indicate potential danger? Can one be reasonably sure that persons who are not dangerous will not be labeled as such and unnecessarily confined? I believe the answer to all these questions is an emphatic "no."

This Article will discuss the psychiatrist's difficulty in predicting dangerousness to others and will propose procedural changes in the handling of potentially dangerous persons. The problem of dangerousness to self will not be discussed here, as it involves quite different clinical and legal problems.

\section{The Glinical Prediction of Dangerousness}

Because of the urgent need for protection against mentally ill persons who are dangerous, and because of the almost universal reliance upon expert psychiatric advice for the preventive detention of such individuals, one would suppose that there existed a sizable amount of valid clinical and research information concerning the prediction of dangerousness. However, there are remarkably few such studies in the scientific literature, and those that do exist have many deficiencies which impair their reliability.

Studies concerning prediction of dangerous behavior fall into two broad categories: those that tend to substantiate clinical predictors and those which demonstrate that such clinical predictions are unreliable. Among the former is an article by Malm-

${ }^{5}$ See, e.g., the Lanterman-Petris-Short Act, CaL. Welf. \& InST'ns Code $\$ \$ 5000-150$ (West 1972).

${ }^{6}$ Rubin, Prediction of Dangerousness in Mentally Ill Criminals, 27 ARCH. Gen. Psychiat. 397 (1972). 
quist, who examined twenty adolescents charged with murder. ${ }^{7}$ Malmquist was specifically interested in the possible existence of premonitory signs and symptoms which could be used to predict violence in other cases. Definite clinical findings were present which were of considerable help in understanding the dynamic process which led up to the homicidal acts. The clinical findings were summarized under the rubrics of behavorial changes prior to the homicidal act; a "call for help" by the juvenile; use of drugs; object losses ${ }^{8}$; threats to manhood; somatization, hypochondiasis, or a recurrent medical problem; an emotional crescendo; and homosexual threats. But, as Malmquist states, "Certain premonitory signs and symptoms culminating in a homicide appeared consistently. But a major difficulty is the prevalence of similar signs and symptoms in people who never commit a violent act." "9

MacDonald followed up one hundred consecutive threatto-kill admissions to the Colorado Psychopathic Hospital. ${ }^{10}$ Within five to six years of the original admission, three of these patients had taken the lives of others and four had committed suicide. Obviously, these seven fatalities are of significance; yet one can hardly justify a preventive detention procedure when over ninety percent of the suspected persons do not commit dangerous acts. In fairness to the clinicians who predicted the dangerousness, it should be noted that it is impossible to estimate how many of those patients might have committed dangerous acts if there had not been the intervention of hospitalization.

Hellman and Blackman have described a triad of symptoms-enuresis, firesetting, and cruelty to animals-which, if exhibited in childhood, are claimed to be predictive of aggressive violent crimes in the adult. ${ }^{11}$ This triad is well known and widely utilized by clinicians in the prediction of dangerousness. Reference to the original report reveals that of thirty-one prisoners charged with aggressive crimes, twenty-three had the full triad. Of fifty-three nonaggressive prisoners, only seven had the full

\footnotetext{
${ }^{7}$ Malmquist, Premonitory Signs of Homicidal Aggression in Juveniles, 128 AM. J. Psychiat. 461 (1971).

${ }^{8}$ In dynamic psychiatry, "object loss" refers to the loss of the object of one's love, such as a lover or mother, and not to the loss of an object as a "thing."

${ }^{9}$ Malmquist, supra note 7 , at 46.

${ }^{10}$ MacDonald, Homicidal Threats, 124 AM. J. Psychiat. 475 (1967).

${ }^{11}$ Hellman \& Blackman, Enuresis, Firesetting and Cruelty to Animals: A Triad Predictive of Adult Crime, 122 AM. J. Psychiat. 1431 (1966).
} 
triad and eight more had a history of part of the triad. This is a very significant clincial difference, but not of a magnitude and consistency to justify involuntary detention on the basis of such predictive criteria. Further, a subsequent study by Climent, Hyg, and Ervin comparing forty emergency room patients brought in because of violent behavior with a matched group of control cases, failed to show a consistent difference in regard to the triad. ${ }^{12}$

Bach-y-Rita and his colleagues have reported the association of head injury and aggressive criminal behavior. ${ }^{13}$ However, Climent and Ervin were subsequently unable to confirm a correlation between severe head injury and adult violence. ${ }^{14}$ They still concluded that there is some relationship between childhood head injury and violent adult behavior, and this corresponds to my own clinical experience. Nevertheless, such an uncertain clinical relationship should not be used as a predictor when the consequence of a false positive prediction is loss of liberty and social stigmatization of a harmless individual.

Various authors have set forth in a pragmatic fashion what they believe are danger signs which indicate potential violence. Usually such assertions claim to be based upon study of hundreds of persons who have killed or threatened to kill. A typical assertion of this sort is made by the psychiatrist David Abrahamsen. ${ }^{15}$ In addition to more obvious signs, such as excessive aggressiveness, temper tantrums, and intense and recurrent fantasies of revenge, Abrahamsen also includes qualities such as loneliness, withdrawal, isolation, and even "speech and spelling errors." 16 He claims that when there is a pronounced incidence of two or more of his fourteen signs, acting out of violent impulses is to be suspected. The absurdity of this claim is demon-

${ }^{12}$ Climent \& Ervin, Historical Data in the Evaluation of Violent Subjects, 27 ARCH. GEN. Psychiat. 621, 624 (1972). But see Wax \& Haddox, Enuresis, Firesetting, and Animal Cruelty in Male Adolescent Delinquents: A Triad Predictive of Violent Behavior, 2 J. PsYch. \& LAw 45 (1974). This report of six dangerously assaultive adolescent boys who exhibited all three symptoms of the triad seems to support the original Hellman \& Blackman study, supra note I1. However, the claim by Wax and Haddox that the triad has predictive value is weakened by their failure to present any information as to the frequency of the triad in non-aggressive children.

${ }^{13}$ Bach-y-Rita, Lion, Climent \& Ervin, Episodic Dyscontrol: A Study of 130 Violent Patients, 127 Aм. J. Psychiat. 1473 (1971).

${ }^{14}$ Climent \& Ervin, supra note 12, at 624.

${ }^{15}$ D. Abrahamsen, Our Vtolent Society 218 (1970).

${ }^{16} \mathrm{Id}$. 
strated by the fact that, by Abrahamsen's own criteria, spelling errors, loneliness, and excessive truancy would, as three such signs, be evidence of dangerousness.

A similar, though more complex, claim is made by Hartogs. ${ }^{17} \mathrm{He}$ lists twelve characterological signs, thirteen developmental signs, fourteen sociological signs, and nine organic (physical) signs, a total of forty-eight predictors of violence. $\mathrm{He}$ gives no statistical or clinical data to support his claim that these forty-eight signs are valid predictors. As with Abrahamsen's signs, some are simply tautological statements that the individual is dangerous, and others are characteristics so widespread that they lose all predictive value in discriminating between the dangerous and the harmless. For example, Hartogs asserts that "[l]ack of family interest, love, support, or acceptance"18 and "[c]onflict over basic identity" 19 are signs of potential violence.

It would be difficult for an objective observer to take such claims seriously if such pseudo-scientific descriptions had not been reiterated so often that they have become part of the accepted mythology of clinical practice. I am sure that many patients have been labeled as dangerous and have been institutionalized for long periods of time upon the basis of such flimsy clinical criteria.

The lack of definitive predictive criteria does not mean that there is not valid scientific evidence for assuming a causative relationship between certain psychological and sociological experiences of the child and adult violence. Further, there is increasing interest in biomedical research on the brain and aggressively violent behavior. ${ }^{20}$ Some claimed discoveries, such as the $\mathrm{XYY}$ chromosomal abnormality and its supposed association with crime, aroused great interest, only to be invalidated by further investigations. ${ }^{21}$ Other studies, in connection with psychosurgery, are surrounded by intense controversy, both sci-

17 Hartogs, Who Will Act Violently: The Predictive Criteria, in VIOLence: CAUSES AND Solutions 332 (R. Hartogs \& E. Artzt eds. 1970).

${ }^{18}$ Id. 335.

${ }^{19}$ Id. 333.

${ }^{20}$ For a thorough, up-to-date review of this biomedical research, see Goldstein, Brain Research and Violent Behavior, 30 ARCH. Neuro. 1 (1974). Goldstein is meticulous in his documentation; hundreds of references to the scientific literature are included.

21 Center for Studies of Crime and Delinguency, National Institute of Mental Health, Report on the XYY Chromosomal Abnormality 33-34 (Public Health Service Pub. No. 2103, 1970). 
entific and political. ${ }^{22}$

Goldstein's comprehensive review of brain research and violence $^{23}$ was based in part upon evaluation discussions of a large group of experienced clinicians. They concluded: "Some of the already agreed upon predictive factors [of an act leading to murder] are a childhood history of maternal deprivation, poor father identification, or both; nocturnal enuresis; possibly fire setting; violence towards animals; and brutalization by one or both parents. ${ }^{24}$

This corresponds to my own clinical experience with both mentally ill and supposedly healthy persons who have committed or attempted murder. I would even say that the conclusion of the clinicians cited by Goldstein represents the sum total of our present scientific knowledge concerning predictive factors of murderous violence. Yet I have repeatedly found some, and sometimes all, of these predictive factors in individuals who have never committed even the slightest harmful act, let alone assault or murder. And I have examined offenders who have committed the most extraordinarily brutal acts of great violence and lethality who possessed none of these factors.

I know of no reports in the scientific literature which are supported by valid clinical experience and statistical evidence that describe psychological or physical signs or symptoms which can be reliably used to discriminate between the potentially dangerous and the harmless individual. The fact that certain signs may sometimes be associated with violent behavior, as, for example, certain types of abnormal brain waves, or that persons who have committed acts of violence tend to reveal in their past histories certain common features, such as an unusual exposure to violence in early childhood, or a higher than average incidence of childhood head injuries, in no way meets the legal need for criteria which will discriminate between the potentially violent and the harmless individual.

\section{Statistical Studies}

There are a number of statistical studies which amply demonstrate that the predictions of dangerousness by psychiatrists

22 Compare V. Mark \& F. ERvin, Violence and the Brain (1970), with Breggin, The Return of the Lobotomy and Psychosurgery, 118 Cong. Rec. 5567 (1972) (extension of remarks of Rep. Gallagher).

${ }^{23}$ Goldstein, supra note 20.

${ }^{24}$ Id. 27. 
are unreliable. ${ }^{25}$ Some of the studies are described in only casual fashion by their authors, but the findings so consistently demonstrate that psychiatrists over-predict dangerousness by huge amounts that the reports must be taken seriously.

Rappeport, director of the pioneer psychiatric court clinic, in Baltimore, has reported:

In 1960 we studied patients who requested sanity hearings or habeas corpus hearings. These were patients committed to one of our state mental hospitals. All had asked to be released, and all had been refused by the hospital and subsequently asked the court to release them. In essence, the hospital had said, we feel you are too dangerous to yourself or the person and property of others to leave. The court released one-third of them after the hearing. Of the remaining two-thirds remanded, one-third subsequently ran away, eloped as we say. The members of the remaining one-third either died, were eventually discharged or are still there. Not one of any of these patients got into any serious difficulty with the law within the 1 to 10 year follow-up period. ${ }^{26}$

Rubin provides a detailed report on the so-called Menard patients. ${ }^{27}$ Seventeen mental patients had been labeled dangerously mentally ill and had been confined to the psychiatric division of the Menard State Penitentiary in Illinois. A series of administrative mix-ups and errors resulted in these seventeen men spending a cumulative 425 years in prison after legislative changes had required their reassignment to treatment or community settings. Rubin describes the shocking story of how these men had been labeled as dangerous as a consequence of an original accusation of a violent crime, a stereotype of dangerousness, and a reaffirmation of the dangerousness, rather than on the basis of any realistic appraisal or clinically competent examination. Rubin personally examined each of the seventeen men and found that in no case was the prediction of dangerousness valid.

The most important statistical study which reflects upon the psychiatric prediction of dangerousness is concerned with the

\footnotetext{
${ }^{25}$ For a bibliography of such studies see Rubin, supra note 6 , at 407.

${ }^{26}$ Rappeport, Dangerousness and the Mentally' Ill Criminal, 21 S.C.L. Rev. 23, 27 (1968).

${ }^{27}$ Rubin, supra note 6 , at 401 .
} 
Baxstrom patients. ${ }^{28}$ New York law permitted prisoners who had completed their maximum sentences and who were believed to be still mentally ill and dangerous to be retained indefinitely in maximum security hospitals for the criminally insane. ${ }^{29}$ The United States Supreme Court, in Baxstrom v. Herold ${ }^{30}$ held that such confinement violated the equal protection clause; as a consequence, 967 such patients were transferred to ordinary, civil mental hospitals.

Steadman, a research sociologist for the New York Department of Mental Hygiene, with others, has made very careful follow-up studies of the 967 Baxstrom cases. ${ }^{31}$ Four and one-half years after the transfer approximately one-third of the Baxstrom patients were free in the community. ${ }^{32}$ Of the entire 967 patients, only twenty-six committed acts serious enough to warrant their return to a maximum security hospital for the criminally insane. ${ }^{33}$ Of these twenty-six returnees, fifteen were returned because of behavior in the hospital defined by the staff as dangerous. ${ }^{34}$ One of these fifteen had made an assault resulting in death; ${ }^{35}$ six had made assaults against persons. ${ }^{36}$ The remaining eleven returnees had been rearrested after their release. ${ }^{37}$ Six of these were found incompetent to stand trial, and were returned to the maximum security hospital for that reason. ${ }^{38}$ The remaining five had been tried, convicted, and then transferred to the institution as psychiatrically disordered criminals. ${ }^{39}$ Two of these last five had committed homicides and a third

${ }^{28}$ The cases were named after Baxstrom v. Herold, 383 U.S. 107 (1966).

${ }^{29}$ Law of April 2, 1929, ch. 243, § 384, [1929] N.Y. Laws 599 (repealed 1966). The statute currently in force authorizes retention of such individuals in ordinary, civil mental hospitals upon completion of their sentence. N.Y. CoRREC. LAw. \& 385 (McKinney 1968).

${ }^{30} 383$ U.S. 107 (1966).

${ }^{31}$ See Halfon, David \& Steadman, The Baxstrom Women: A Four Year Follow-Up of Behavior Patterns, 45 PsychIaT. Q. 518 (1971); Steadman, Follow-Up on Baxstrom Patients Returned to Hospitals for the Criminally Insane, 130 AM. J. Psychiar. 317 (1973); Steadman \& Halfon, The Baxstrom Patients: Backgrounds and Outcomes, 3 Sem. Psychiat. 376 (1971); Steadman \& Keveles, The Community Adjustment and Criminal Activity of the Baxstrom Patients: 1966-1970, 129 AM. J. Psychiat. 304 (1972). See generally Hunt \& Wiley, Operation Baxstrom After One Year, 124 Am. J. Psychiat. 974 (1968).

${ }^{32}$ Steadman, supra note 31, at 317; Steadman \& Keveles, supra note 31 , at 305 . Of a different sample of 246 Baxtrom patients, $17 \%$ were arrested at some time. Id. 307-08.

${ }^{33}$ Steadman, supra note 31 , at 317.

${ }^{34}$ Id. 318.

${ }^{35} I d$.

${ }^{36} I d$.

${ }^{37}$ Id.

${ }^{38} I d$.

${ }^{39} I d$. 
committed a second degree assault. ${ }^{40}$

Steadman has attempted to differentiate the twenty-six returnees from the other 941 patients. He found that the returnees tended to be much younger than the others, with an average age of thirty-three, as opposed to forty-seven for the non-returnees. ${ }^{41} \mathrm{He}$ also found that the returnees' scores on a "Legal Dangerousness Scale" (based on the history of criminal behavior prior to institutionalization) were significantly higher than the non-returnees'. ${ }^{42}$ However, this could not be used for prediction of the necessity for return, for over ninety percent of the patients with such a high score did not have to be returned. ${ }^{43}$

I believe it is clear from the Baxstrom studies that of these 967 persons who had been convicted at one time of serious crimes, and who were designated as mentally ill and dangerous to others in order to justify their further confinement, only a very few were actually dangerous. One can only conclude that psychiatrists who make such judgments tended to over-predict dangerousness greatly, by a factor somewhere between ten and a hundred times the actual incidence of dangerous behavior. It is understandable why this should be so. If the psychiatrist underpredicts danger, and clears a patient who later commits a violent act, he will be subjected to severe criticism. If, on the other hand, he over-predicts danger, he will suffer no consequence from such faulty prediction, for his prediction might have come true had there been no intervention (such as institutionalization). In general, if the psychiatrist predicts that there is no danger, the feed-back from an erroneous prediction is real and immediate. If he predicts that there is danger, there may be no feed-back, or, if there is, it may not be possible to interpret it in ways which would improve the predictive ability of the psychiatrist. Inevitably, this will result in all concerned doing the "safe" thing: predicting dangerousness, if there are even the most minimal reasons to justify it.

\section{Mental Illness and Dangerousness}

One factor which has impeded the ability of psychiatrists to predict the dangerousness of mentally ill persons accurately is

to Id. 319.

11 Id. 31.7.

${ }^{42}$ Id.

${ }^{4}$ Id . 
the lack of a clear-cut association between mental illness (or any particular form of mental illness) and dangeous behavior. Rappeport and Lassen were able to determine the post-hospitalization arrest rates for all male patients over sixteen years of age discharged from all but one of Maryland's psychiatric hospitals during the fiscal years 1947 and 1957.44 Their data, when compared to the arrest rates of the similar male population of the state as a whole, revealed that the rate for robbery was significantly higher in the mental patients; the data also suggested that there may have been a higher incidence of rape by the mental patients before their hospitalization, but there was no evidence that murder, negligent manslaughter, or aggravated assault offenses were more common among the discharged hospital patients than in the general population. ${ }^{45}$ Other studies ${ }^{46}$ tend to show a lesser involvement in criminal behavior by the mentally ill than is true for the general population.

Guze and his associates at Washington University have published many reports on the possible relationship of mental illness and crime. ${ }^{47}$ Their studies demonstrate that those conditions which are most clearly recognized as mental illness, such as schizophrenia and the other psychoses, are not found significantly more often in the criminal population. ${ }^{48}$ On the other hand, psychiatric conditions such as sociopathy, alcoholism, drug dependence, and (among women offenders) hysteria were frequently associated with adult criminality. ${ }^{49}$ But these latter conditions are precisely those psychiatric states which are less easily

${ }^{44}$ Rappeport \& Lassen, Dangerousness-Arrest Rate Comparisons of Discharged Patients and the General Population, 121 Aм. J. PsychIAT. 776, 777 (1965).

${ }^{45}$ Id. 779.

${ }^{46}$ Cited and summarized in $i d .776$.

${ }^{47}$ See, e.g., Cloninger \& Guze, Psychiatric Illness and Female Criminality: The Role of Sociopathy and Hysteria in the Antisocial Woman, 127 AM. J. Psychiat. 303 (1970); Guze, Goodwin \& Crane, Criminality and Psychiatric Disorders, 20 Arch. Gen. Psychiat. 583 (1969); Guze, Tuason, Gatfield, Stewart \& Ricker, Psychiatric Illness and Crime with Particular Reference to Alcoholism: A Study of 223 Criminals, 134 J. NERv. \& MENT. Dis. 512 (1962); Guze, Woodruff \& Clayton, Hysteria and Antisocial Behavior: Further Evidence of an Association, 127 AM. J. Psychiat. 957 (1971); Guze, Woodruff \& Clayton, The Medical and Psychiatric Implications of Antisocial Personality (Sociopathy), 32 Dis. Nerv. Syst. 712 (1971).

${ }^{48}$ Guze, Goodwin \& Crane, supra note 47; Guze, Tuason, Gatfield, Stewart \& Ricker, supra note 47; Guze, Woodruff \& Clayton, Psychiatric Disorders and Criminality, supra note 47.

49. See Cloninger \& Guze, supra note 47; Guze, Goodwin, \& Crane, supra note 47; Guze, Tuason, Gatfield, Stewart \& Ricker, supra note 47; Guze, Woodruff \& Clayton, Psychiatric Disorders and Criminality, supra note 47; Woodruff, Guze \& Clayton, supra note 47. 
definable and less generally agreed to be illnesses at all. "[E]xcept for [these conditions] and for sexually deviant behavior leading to arrest and conviction, other psychiatric disorders are infrequently associated with felonies." 50

Psychiatrists as well as courts tend to perceive dangerousness as an attribute of an individual, as a quality which one ought to be able to define, detect, and measure. Important decisions are made based upon the presence or absence of this quality of dangerousness, decisions which may result in the lifetime incarceration of a person so designated. If the quality of dangerousness is determined to be absent, as in the Kemper case, the lives of many others may be jeopardized.

Theodore Sarbin, a psychologist and criminologist, has argued that the concept of danger and the concept of violence are not coterminous, that danger always denotes a relationship. He concludes that danger must not be construed as the expression of a personality trait, but rather as a relationship of relative power. ${ }^{51}$ Sarbin has emphasized the process of reification, the process by which action or behavior becomes translated into an attribute of the person. This is an extremely important concept. For example, stealing is an action. To label a man who steals as a thief is to reify the action into an attribute. It implies that the man will continue to steal no matter what the situation, and that his thieving behavior is a consequence only of factors within him. For the same reason, one should not label a man who acts violently and causes harm as dangerous, for by so doing one has transformed an action into an attribute and has knowingly or unwittingly made the prediction that there will be future acts of violence, and that these future acts will be determined by qualities of the individual, not by the relationship or the circumstances. Although it may be convenient to label persons, to reify behavior into attributes, and thus to predict future conduct, it must be recognized that such a process has no scientific or logical basis and that there is no reason to expect that such predictions will come true.

Even if one accepts a simplistic concept of dangerousness, such as a propensity to commit criminal acts, should one regard 641 .

${ }^{50}$ Guze, Woodruff \& Clayton, Psychiatric Disorders and Criminality, supra note 47 , at

${ }^{1}$ Sarbin, The Dangerous Individual: An Outcome of Social Identity Transformations, 7 BRIT. J. CRIM. 285 (1967). 
dangerousness to property as being of the same social significance as violence to the person of others? It is remarkable that discussions of dangerousness so often fail to specify the nature of the danger. Clearly, it makes a difference to society if an offender is dangerous to property because of his need to write graffiti on subway walls or if he is dangerous because he molests little children or has an uncontrollable impulse to murder. Yet some statutes completely ignore such distinctions, and give the forensic psychiatrist no guidance. ${ }^{52}$

Restricting the definition of dangerousness to the propensity for violence is of no help, for violence itself is extremely difficult to define.

No definition of violence has ever proved completely successful. Although everyone "knows what violence is" no one has ever been able to define it adequately so that every possible instance of violent behavior is included within the definition while all the excluded behavior is clearly nonviolent. The working definition that has been adopted for the purposes of this Task Force is that acts of violence mean the "overtly threatened or overtly accomplished application of force which results in the injury or destruction of persons or property or reputation, or the illegal appropriation of property."53

Such definitions are either so vague or so all-inclusive that no reliance can be placed upon them in seeking to differentiate the harmless from the dangerous. When such difficulties are coupled with the even greater problems of defining mental illness, sanity, and insanity, ${ }^{54}$ it is no wonder that gross confusion exists and that the psychiatric predictions are devoid of validity and reliability.

52 See, e.g., CAL. Welf. \& INST'NS CODE $§ 5150$ (West 1972), which specifies "danger to others, or to himself," as grounds for involuntary hospitalization. Even when statutes define the general area of dangerousness, as is true for most "sexual psychopath" laws, they are still so vague as to preclude any rational distinction between those who should be confined and those who should not. California, for example, defines a "mentally disordered sex offender" as "any person who by reason of mental defect, disease, or disorder, is predisposed to the commission of sexual offenses to such a degree that he is dangerous to the health and safety of others." Id. § 6300.

${ }^{33}$ Megargee, $A$ Critical Review of Theories of Violence, in 3 Crimes of VIolence: A Staff Report Submitted to the National Commission on the Causes \& Prevention OF VIOLENCE 1037, 1038 (1969).

${ }^{54}$ See generally Rosenhan, On Being Sane in Insane Places, 179 SCIENCE 250 (1973). 


\section{No Means of Prediction Exist}

There is an unfortunate tendency in the psychiatric literature to imply that the scientific answers to pressing social problems which are not now capable of solution are likely to be available in the very near future, if only there is a bit more research. Optimistic statements such as the following abound: "Elaboration of methods for recognizing and understanding aggressive patients may enable us to manage them or treat them in ways which will reduce or eliminate their dangerousness and thus permit the restoration of their liberty." 55

Realistically, it is more likely that the increase in our scientific knowledge of human behavior, derived from both psycological and sociological sources, will increase, rather than decrease, the difficulty in applying such knowledge to legal issues. Increased knowledge brings complexity rather than simplicity, uncertainty rather than certainty, frequently blurring distinctions rather than clarifying them. This knowledge thus becomes less helpful to the all-or-none, two-valued decisionmaking process of the law. ${ }^{56}$

The evidence, as well as the consensus of opinion by responsible scientific authorities, is now unequivocal. At a recent international conference there was general agreement by psychiatrists and sociologists from many nations with the views expressed by $\mathrm{N}$. Christie, Professor of Criminology at the University of Oslo: "There seems to be no convincing study to show that we can predict really dangerous behavior with any amount of acceptability." 57

Finally, the Alcohol, Drug Abuse, and Mental Health Administration of the Department of Health, Education, and Welfare stated in a press release dated August 8, 1974: "Although the psychiatric profession is frequently called upon to predict the

55 Scott, Violence in Prisoners and Patients, in Medical Care of Prisoners and Detainees 143, 152 (Ciba Foundation Symposium 16 (n.s.), 1973. I have been equally guilty of making such optimistic predictions as to the ability of psychiatric science to discover new information of great value to the law. See Diamond, From M'Naghten to Currens, and Beyond, 50 CaLIF. L. REv. 189, 198 (1962).

${ }^{56}$ See generally Diamond, From Durham to Brawner, a Futile Journey, 1973 WAsH. U.L.Q. 109, 111-15 (1973).

${ }^{57}$ Scott, supra note 55, at 153. Rappeport, Lassen, and Hay make a similar statement: "[T] $[$ here are no articles that would assist us to any great extent in determining who might be dangerous, particularly before he commits an offense." Rappeport, Lassen \& Hay, $A$ Review of the Literature on the Dangerousness of the Mentally Ill, in THE Clinical Evaluatron of the Dangerousness of the Mentally Ill 72, 79 (J. Rappeport ed. 1967). 
potential dangerousness of persons brought before the courts, no scientifically reliable method for predicting dangerous behavior exists."58

Neither psychiatrists nor other behavioral scientists are able to predict the occurrence of violent behavior with sufficient reliability to justify the restriction of freedom of persons on the basis of the label of potential dangerousness. Accordingly, it is recommended that courts no longer ask such experts to give their opinion of the potential dangerousness of any person, and that psychiatrists and other behavioral scientists acknowledge their inability to make such predictions when called upon to do so by courts and other legal agencies.

When appropriate legal authority has declared a person dangerous, upon the basis of evidence of demonstrated violent behavior, psychiatrists and other experts on human behavior may be called upon to give their opinion whether the dangerous behavior is a consequence of, or related to, the existence of mental or emotional illness. Such experts may also be called upon to give their opinions whether the so-called institutional or treatment program "medical model" is appropriate for remedying the dangerous condition and protecting society against the danger. They should not be asked to do more. 1974).

${ }^{58}$ U.S. Dep't of Health, Education and Welfare, HEW News (News Release, Aug. 8, 